\section{Crystallographers' proteins}

\author{
Kenneth C. Holmes
}

Diffraction Methods for Biological Macromolecules, Parts A and B. Methods in Enzymology Vols 114 and 115. Edited by Harold W. Wyckoff, C.H.W. Hirs and Serge N. Timasheff. Academic: 1985 . Part A pp.588, \$70.50, £59. Part B pp.485, $\$ 66.50, £ 50.50$.

THE structural investigation of protein crystals by X-ray diffraction started in 1934, when J.D. Bernal and Dorothy Crowfoot Hodgkin first successfully photographed a crystal of pepsin. The resulting X-ray diffraction patterns contained so many Bragg reflections that they resisted all known methods of interpretation for 20 years, until Max Perutz was able to show that the small changes in $\mathrm{X}$ ray intensities induced by binding two mercury atoms per molecule of haemoglobin were enough to determine the phase of each reflection. With phases, the electron density can be calculated, albeit by evaluating a Fourier series of around 10,000 terms at each of 100,000 lattice points! Another five years elapsed before John Kendrew's team could carry out a Fourier synthesis for myoglobin to atomic resolution, revealing for the first time the intricacies of the three-dimensional structure of a protein.

Kendrew used programs devised to run on the Cambridge Mathematical Laboratory's EDSAC II. Without such a machine the calculation of the electron density of myoglobin would have been virtually impossible; indeed, the growth of protein crystallography is intimately entwined with the development of the computer.

In the $1950 \mathrm{~s}$, because of the influence of Sir Lawrence Bragg and the activities of Perutz and Kendrew, protein crystallography was synonymous with the Medical Research Council unit in the Cavendish Laboratory. (Later, other centres appeared, but even these, in most cases, trace back in apostolic succession to Bernal or Bragg.) In the late 1950s and 1960 s, then, a stream of (mostly American) post-doctorate students descended on the MRC unit and worked feverishly to turn protein crystallography into an established science worthy of associate professorships. Now they and their acolytes, and some converts, have written it all down.

The articles in the resulting two volumes are rather technical or mathematical. They are also somewhat uneven in type, ranging from user's guides for various program packages to some thoughtful review papers. Thus, while specialists will find a wealth of useful detail here, those less familiar with the field could have trouble finding their way around. The contributions are grouped in sections: history (an engrossing article by Perutz); crystallization (the nearest we get to wet biochemistry); data collection; phasing; model building; and presentation of results.

Michael Rossmann, who was in at the start on EDSAC II, contributes a detailed and informative chapter on oscillation photography. Other mandarins also make interesting contributions: Fred Richards concerns himself with the problem of defining protein surfaces and, besides, reviews his folly. David Stuart and David Phillips present an excellent analysis of thermal motion and its relationship to molecular dynamics — otherwise hardly mentioned. Hal Wyckoff, also an editor, has provided a definitive review of diffractometry. Jane Richardson's stylized drawings of proteins are truly beautiful, while Lynn Ten Eyck deserves a prize for the most concise account of X-ray diffraction. A summary of the least-squares

\section{The common quest}

\section{A.R. Rees}

Growth Factors and Transformation. Edited by James Feramisco, Brad Ozanne and Charles Stiles. Cold Spring Harbor Laboratory: 1985. Pp.450. Pbk\$70.

IN its application to the study of oncogenic transformation, the inductive approach to science has perhaps come under closer scrutiny than in any other area of biology. While it is generally agreed that cancer is not a single disease, this has not prevented researchers from assuming that common mechanisms will emerge if we just look long enough and hard enough. This is by no means obvious. For example, that tyrosine phosphorylation is a causal event in transformation was and remains an attractive hypothesis; but there is still not a single example in which specific substrates of tyrosine kinases can be said to play a key role in the transformation process, although the presence of the kinase itself is often sufficient to transform the target cell. Even if plausible mechanisms for oncogenic transformation were to emerge, we are still left with the problem of how they would relate to transformation in vivo - despite the fact that some 30 oncogenes have been characterized that originate within the cell and 10 or so others from within oncogenic viruses.

It was against this background that, in the autumn of 1984, Cold Spring Harbor Laboratory organized its meeting on growth factors and transformation. The subject matter in the resulting book is arranged loosely into chapters, the first five method has been contributed by Robert Sparks, though this is somewhat out of place in the "phasing" section. No less than 12 articles use the least-squares method and the consistent adoption of Sparks's notation throughout the book would have helped clarity.

The article by Joel Sussman on constrained least-squares refinement reawakened my memories of 1963 , when Carl Branden and myself battled with an IBM 7090 for 16 hours to achieve one cycle of constrained refinement of myoglobin. Progress indeed! Once or twice elsewhere I experienced déjà $v u$; for example, mirror benders turn up attributed to all and sundry, but not to Tony Woollard who actually developed the present design in Cambridge. This reflects the fact that in the heady years of the 1960 s the rate of innovation outstripped the rate of publication. The present volumes redress the balance with a little to spare.

Kenneth C. Holmes is Chairman of the MaxPlanck-Institut für Medizinische Forschung, Jahnstrasse 29, 6900 Heidelberg, FRG.

of which survey the properties of growth factors (epidermal growth factor, transforming growth factors, insulin and the related insulin-like growth factors, platelet-derived growth factor and its oncogenic relatives, and, finally, the lymphokines). The second half of the proceedings is devoted to oncogenes and kinases, with a concluding chapter entitled "Futures". In the main each author provides an integrated account of the interplay between growth factors and oncogenes, but the existence of genes for which a growth factor connection (or in some instances, function) has not been established necessitated their collection into the separate chapter on oncogenes. For a number of these oncogenes (E1A, Ha-ras-1, c-fos, c$m y b$, for example) this biological apartheid would still be necessary.

There are always things to be said for and against conference proceedings, even up-market productions such as those emanating from Cold Spring Harbor. In a fast moving field like this, speed is crucial. Unless the proceedings appear within six months they are generally of dubious value to research workers, though they may be useful as background reading for those at the periphery. Growth Factors and Transformation appeared in Britain almost a year after the conference. This delay would have mattered less if some of the chapters had not been quite so repetitive. And this criticism might have been redundant if the meeting itself had not been so parochial - only four papers were contributed by groups working wholly outside the United States.

The repetitive element is at one of its high points in the opening chapter on epidermal growth factor, and is also a feature 